\title{
3,4-Dihydroxybenzoic acid removal from water by goethite modified natural sand column fixed-bed: experimental study and mathematical modeling
}

\author{
Hassan Ouachtak ${ }^{a, b}, *$, Siham Akhouairic ${ }^{c}$, Redouane Haounatic ${ }^{c}$ Abdelaziz Ait Addic, \\ Amane Jada ${ }^{\mathrm{d}, e, *}$, Mohamed Labd Taha ${ }^{\mathrm{a}}$, Jamaa Douch ${ }^{\mathrm{c}}$ \\ ${ }^{a}$ Laboratoire de Chimie Appliquée E Environnement, Equipe Bio-organique Appliquée, Faculté des Sciences, Université Ibn Zohr, \\ Agadir, Maroc, emails: ouachtakhassan@gmail.com (H. Ouachtak), labd999@gmail.com (M.L. Taha) \\ ${ }^{b}$ Faculté des Sciences Appliquées Ait Melloul, Université Ibn Zohr, Agadir, Maroc \\ 'Département de chimie, Faculté des Sciences, Université Ibn Zohr, Agadir, Maroc, emails: akhouairisiham@gmail.com (S. Akhouairi), \\ haounati.redouane@gmail.com (R.Haounati),a_aitaddi@yahoo.fr (A.A. Addi),douch.791955@gmail.com (J. Douch) \\ ISIM, CNRS-UHA, 15 Rue Jean Starcky, 68057 Mulhouse cedex, France, Tel. 00333 89608709; email: amane.jada@uha.fr (A. Jada) \\ 'Université de Strasbourg, Strasbourg, F-67081, France
}

Received 14 August 2019; Accepted 3 February 2020

A B S T R A C T

In this paper, a continuous adsorption of 3,4-Dihydroxybenzoic acid (3,4-DHBA) has been studied by using goethite modified natural sand (GMNS) as adsorbent in a fixed-bed column. Scanning electron microscopy coupled with energy-dispersive X-ray analysis, X-ray diffraction and Fourier transform infrared spectroscopy (FTIR), characterized the GMNS surface. The effect of various experimental parameters including $\mathrm{pH}(5$ and 9$)$, flow rate $(1,2$, and $3 \mathrm{~mL} / \mathrm{min})$ and initial 3,4-DHBA concentration $(15,40$ and $60 \mathrm{mg} / \mathrm{L})$ on the transport and adsorption of 3,4-DHBA onto the column were investigated in detail. The obtained result shows that exhaustion time decreased with increasing initial 3,4-DHBA concentration, flow rate and $\mathrm{pH}$. The highest value of adsorbed amount $q=35.66 \mathrm{mg} / \mathrm{Kg}$ was obtained from injection of $60 \mathrm{mg} / \mathrm{L}$ of initial 3,4-DHBA concentration solution with flow rate, $Q=1 \mathrm{~mL} / \mathrm{min}$, at $\mathrm{pH}=5$ in column packed with GMNS. The Thomas and Yoon-Nelson models were applied to describe the breakthrough curves of adsorption of 3,4-DHBA onto GMNS solid. The linear regression analysis demonstrated that the Yoon-Nelson model fitted well with the column adsorption data for 3,4-DHBA. In addition, adsorption mechanism was proposed based on the results FTIR before and after adsorption. The GMNS adsorbent can be regenerated for three adsorption-desorption cycles using sodium hydroxide solution.

Keywords:3,4-DHBA adsorption; Goethite modified natural sand; Column fixed-bed; Transport; Modeling

\footnotetext{
* Corresponding authors.

Presented at the 7th International Conference on Sustainable Solid Waste Management, $26-29$ June 2019, Heraklion, Crete Island, Greece 1944-3994/1944-3986 ㄷ 2020 Desalination Publications. All rights reserved.
} 